\title{
APLIKASI HELMHOLTZ RESONATOR DENGAN VARIASI JUMLAH MONONECK DALAM ARAH LONGITUDINAL PADA INLET MANIFOLD MOTOR DIESEL
}

\section{SUPERCHARGING 4 TAK}

\author{
Mesak Frits Noya ${ }^{1}$, Abdul Hadi ${ }^{2}$ \\ E-mail: : ${ }^{1}$ frits.noya@,fatek.unpatti.ac.id, ${ }^{2}$ abdulhadi@,fatek.unpatti.ac.id \\ Program Studi Teknik Sistem Perkapalan, Fakultas Teknik Universitas Pattimura
}

\begin{abstract}
ABSTRAK
Penelitian ini bertujuan untuk mengetahui pengaruh Circular Helmholtz Resonator dengan variasi jumlah Mononeck pipa kapiler terhadap Supercharging yang digerakan elektromotor. Penelitian eksperimenal ini dilakukan dengan 6 variasi Mononeck yang dipasang secara longitudinal up side down. Piezotronics, National Instrument dan Matlab digunakan untuk mengakuisisi data menjadi lebih akurat. Hasil pengukuran selisih rata-rata tekanan output dan input menyatakan bahwa Circular Helmholtz Resonator berpengaruh terhadap tekanan udara keluaran yang merupakan tekana udara input motor diesel.
\end{abstract}

Kata Kunci : Circular Helmholtz Resonator, Mononeck pipa kapiler, Inlet Manifold, Tekanan

\section{PENDAHULUAN}

Mesin-mesin diesel yang diproduksi saat ini, adalah sangat efisien sehingga mampu memberikan daya yang maksimal. Efisiensi kenaikan daya mesin diesel dalam penggunaan supercharger adalah dengan meningkatkan suplai udara bersih ke dalam ruang bakar. Supercharger ialah sebuah kompresor gas digunakan untuk memompa udara bersih ke silinder mesin pembakaran dalam. Massa oksigen tambahan yang dipaksa masuk ke silinder membuat mesin membakar lebih banyak bahan bakar, dan meningkatkan efisiensi pengisian mesin dan membuatnya lebih bertenaga. Sebuah supercharger menerima suplay tenaga yang dihubungkan dengan crankshaft mesin melalui pulley sehingga unggul pada putaran bawah karena perangkat ini sudah mulai bekerja pada rpm rendah. RPM supercharger bisa diatur dengan menggunakan diameter pulley yang berbeda. Semakin kecil driven pulley supercharger, maka RPM supercharger akan semakin tinggi dan menghasilkan tekanan yang tinggi juga. Cara lain untuk meningkatkan tekanan udara agar efisiensi mesin dapat lebih tinggi adalah dengan menggunakan helmholtz resonator. Helmholtz resonator bekerja dengan memanfaatkan peristiwa resonansi udara dalam suatu rongga.

Fakultas Teknik Universitas Pattimura,

ISSN : 2620-3995
Resonator tersebut terdiri dari suatu badan yang berbentuk bola dengan sebuah leher. Ketika udara masuk melalui leher resonator, tekanan dalam rongga badan resonator akan meningkat dan gaya luar yang menekan resonator akan hilang, sehingga udara yang berada didalam resonator akan bergerak keluar melalui leher resonator. Dengan mengaitkan supercharger yang meningkatkan volume udara kedalam ruang bakar dan helmholtz resonator yang meningkatkan tekanan melalui rongga, maka penulis berinisiatif untuk melakukan studi eksperimental untuk meningkatkan tekanan udara masuk pada inlet manifold dengan memberikan variasi berupa jumlah mononeck helmholtz resonator dalam arah longitudinal. Tujuan dari penelitian ini adalah untuk mengetahui pengaruh helmholtz resonator dengan variasi jumlah mononeck pipa kapiler dalam arah longitudinal terhadap supercharging aftercooler pada inlet manifold.

\section{KAJIAN TEORI DAN METODE KAJIAN TEORI}

Resonansi Helmholtz merupakan peristiwa resonansi udara dalam suatu rongga. Resonator tersebut terdiri dari suatu badan yang berbentuk 
bola dengan satu volume udara dengan sebuah leher.

Bayangkan bahwa aliran fluida di dalam suatu horizontal pipeline dikalkulasi dengan assumsi: koordinat spasial 1-D, viscos, adiabatic, homogen, small fluctuacion dan jika $\mathrm{p}$ dan $\mathrm{q}$ masing-masing menyatakan tekanan dan laju massa aliran fluida sebagai koordinat spasial dan waktu.

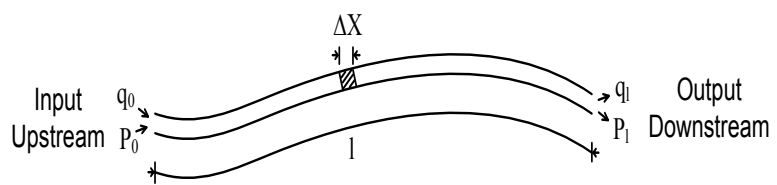

Gambar 1. Non-Causal Model of Fluid Flow

$\mathrm{x}=$ Space (1-D) dalam arah aliran fluida $[\mathrm{m}]$ $q=A_{l} \bar{\rho} V[\mathrm{Kg} / \mathrm{s}]$

Dimana:

$A_{l}=$ Luas penampang pipeline profile $\left[\mathrm{m}^{2}\right]$

$\bar{\rho}=$ Densitas rata-rata $\left[\mathrm{Kg} / \mathrm{m}^{3}\right]$

$\mathrm{V}=$ Kecepatan aliran fluida dalam pipeline $[\mathrm{m} / \mathrm{s}]$

$\mathrm{P}=\mathrm{P}(\mathrm{x}, \mathrm{t})=$ Tekanan $\left[\mathrm{N} / \mathrm{m}^{2}\right]$

$\mathrm{Q}=\mathrm{q}(\mathrm{x}, \mathrm{t})=$ Laju aliran massa $[\mathrm{Kg} / \mathrm{s}]$

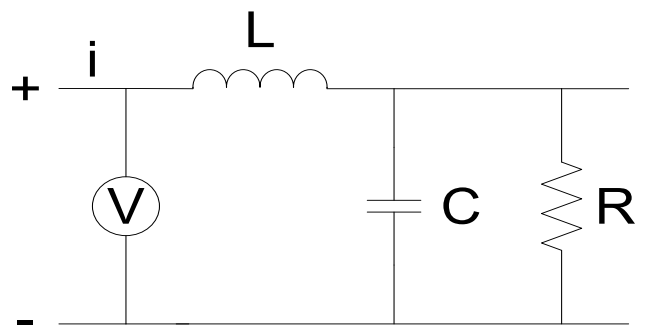

Gambar 2. Electrical Transmission Analogical Model

\section{METODE PENELITIAN}

Penelitian dilakukan dengan menggunakan peralatan seperti pada gambar berikut

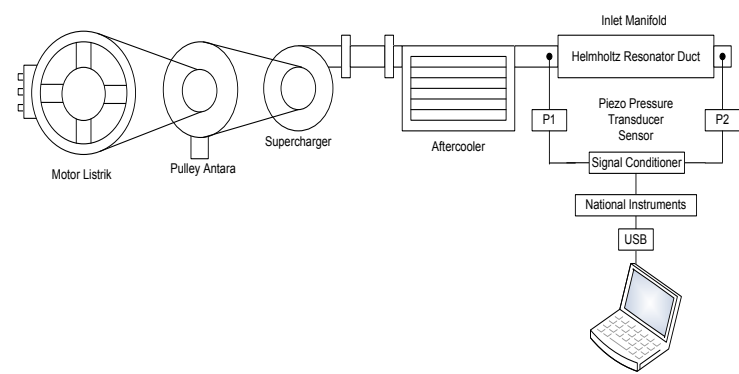

Gambar 3. Rancangan Peralatan

Fakultas Teknik Universitas Pattimura,

ISSN : 2620-3995

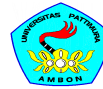

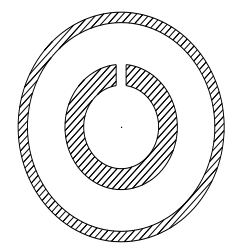

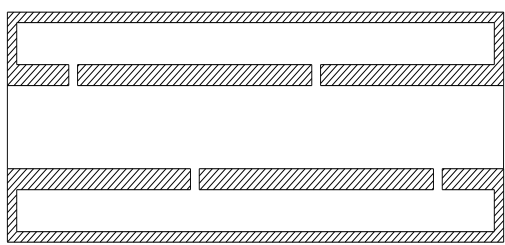

Gambar 4. Rancangan Mononeck Circular Helmholtz Resonator dalam arah longitudinal

\section{HASIL DAN PEMBAHASAN}

Pengambilan data dilakukan sebanyak 10 kali untuk input dan output per variasi. Kemudian diulang lagi sebanyak 10 kali untuk pengambilan data noise. Data tersebut diperoleh setelah motor listrik dijalankan dan terhubung langsung dengan Helmholtz Resonator dan sensor, kemudian data tersebut diolah dengan menggunakan program Matlab. Data yang direkam sensor dapat dilihat dalam grafik sebagai berikut:
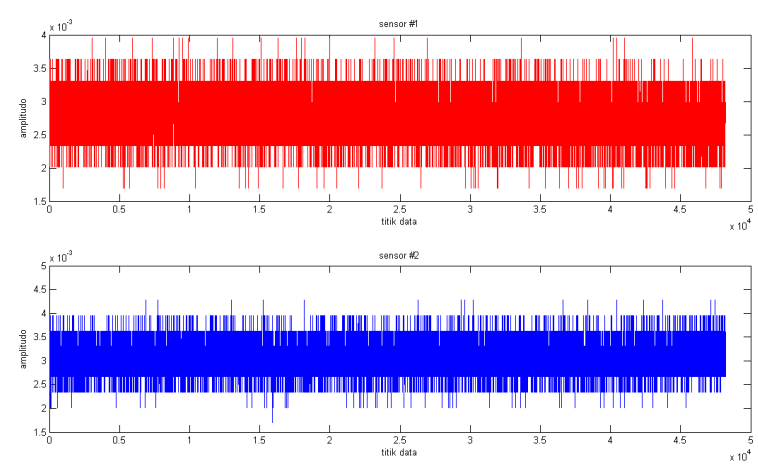

Gambar 5. Data yang direkam sensor input (sensor \#1) dan output (sensor \#2) pada variasi ke-1
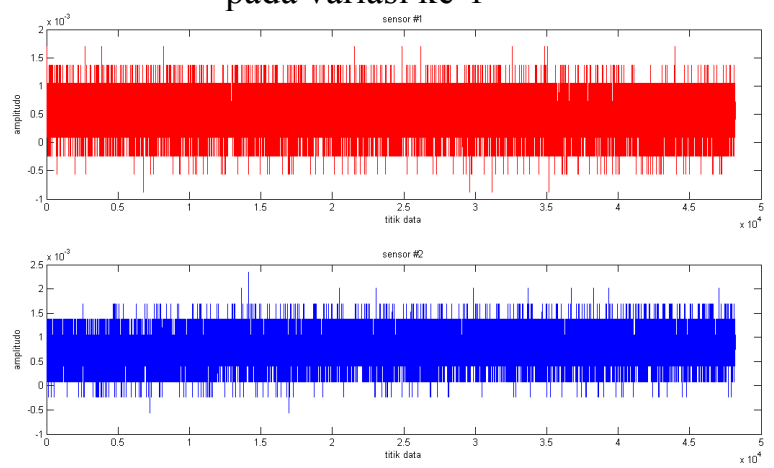

Gambar 6. Data yang direkam sensor input (sensor \#1) dan output (sensor \#2) pada variasi ke-4 


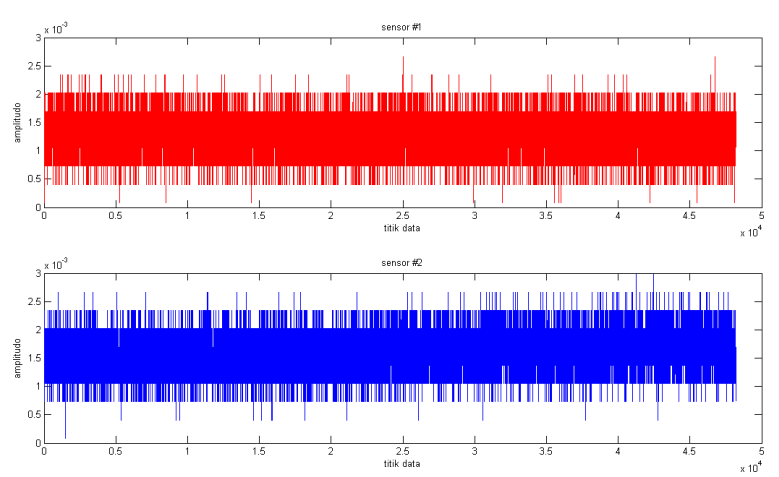

Gambar 7. Data noise yang direkam sensor input (sensor\#1) dan output

(sensor\#2) pada variasi ke-1
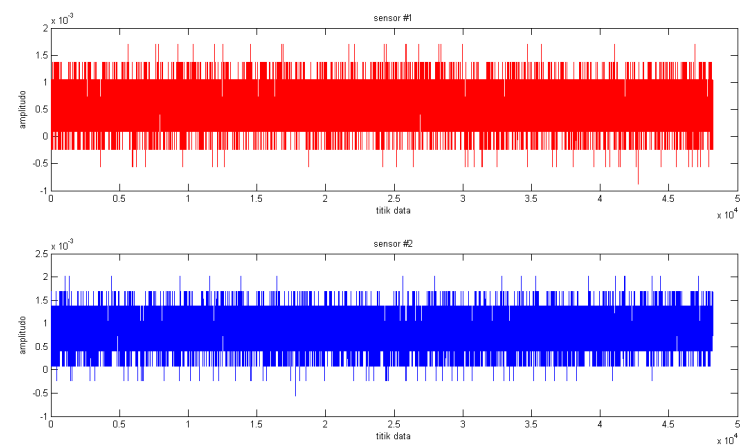

Gambar 8. Data noise yang direkam sensor input (sensor\#1) dan output

(sensor\#2) pada variasi ke-4

Setiap data yang diperolah mempunyai titik data sebanyak 48192, sehingga keakuratan data juga dapat dipertahankan. Kemudian data ini akan disaring (filter) dengan menerapkan metode Wiener Filter dengan pendekatan Weighting Function (fungsi bobot). Data input dan output ini kemudian dijumlahkan dengan data noise input dan output untuk dicari nilai rata-rata dari data tiap variasi. Nilai rata-rata data ini kemudian digabungkan dengan nilai rata-rata data untuk setiap pengulangan per variasi (tiap variasi pengulangan sebanyak 10 kali untuk input dan output) sehingga membentuk matriks nilai rata-rata data.
Tabel 1. Data hasil pengukuran tekanan aliran udara input dan output untuk setiap variasi Helmholtz Resonator

\begin{tabular}{|c|c|c|l|l|}
\hline $\begin{array}{c}\text { Variasi } \\
\text { Helmholtz } \\
\text { Resonator }\end{array}$ & $\begin{array}{c}\text { Rata-rata } \\
\text { Tekanan } \\
\text { Input } \\
\left(\mathrm{N} / \mathrm{m}^{2}\right)\end{array}$ & $\begin{array}{c}\text { Rata-rata } \\
\text { Tekanan } \\
\text { Output } \\
\left(\mathrm{N} / \mathrm{m}^{2}\right)\end{array}$ & $\begin{array}{c}\text { Rata-rata } \\
\text { Tekanan } \\
\text { Output- } \\
\text { Input } \\
\left(\mathrm{N} / \mathrm{m}^{2}\right)\end{array}$ & $\begin{array}{c}\text { Persentasi } \\
\text { Rata-Rata } \\
(\%)\end{array}$ \\
Variasi 1 & 101318.95 & 101392.87 & 73.92 & 0.07 \\
Variasi 2 & 101401.37 & 100791.89 & $-6.09 \times 10^{2}$ & -0.60 \\
Variasi 3 & 101323.53 & 101269.10 & -54.43 & -0.05 \\
Variasi 4 & 101324.96 & 101341.04 & 16.08 & 0.01 \\
Variasi 5 & 101306.19 & 101305.33 & -0.85 & $-8.46 \times 10^{-4}$ \\
Variasi 6 & 101330.06 & 101334.80 & 4.73 & $4.67 \times 10^{-3}$ \\
\hline
\end{tabular}

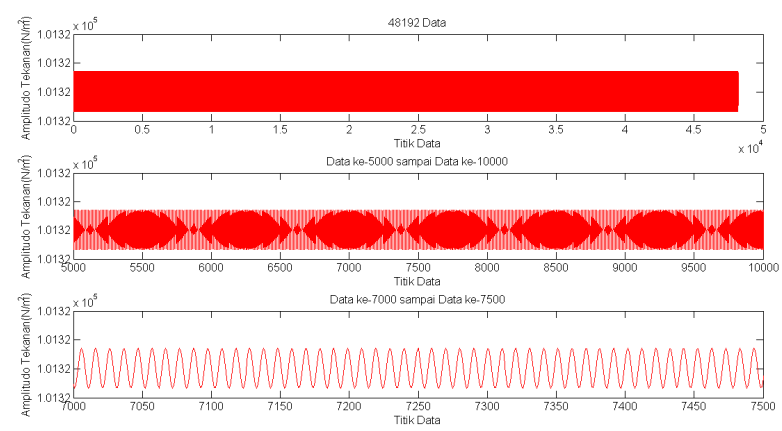

Gambar 9. Grafik tekanan input (Pnin) pada variasi ke-1

Pada grafik pertama dari gambar 9. dapat dilihat bahwa grafik plot tekanan input pada variasi pertama sangatlah padat terhadap sumbu $\mathrm{x}$ dan amplitudonya sangat stabil, sehingga menjadi sulit untuk dapat melihat karakteristik dari gelombang tekanan yang ada. Untuk itu pada grafik kedua dan ketiga dari gambar 9 . dibuka skalanya menjadi data ke-5000 sampai ke-10000 dan data ke-7000 sampai data ke-7500 agar dapat melihat karakteristik gelombang yang ada.

Hasil tekanan yang didapati sangatlah banyak untuk setiap variasi Helmholtz Resonator yang ada, dikarenakan titik data sebanyak 48192. Untuk itu agar memudahkan melihat amplitudo data dan karakteristik gelombang yang sangat rapat digunakan grafik dengan format semilog terhadap sumbu $\mathrm{x}$ dengan nilai 48192. 


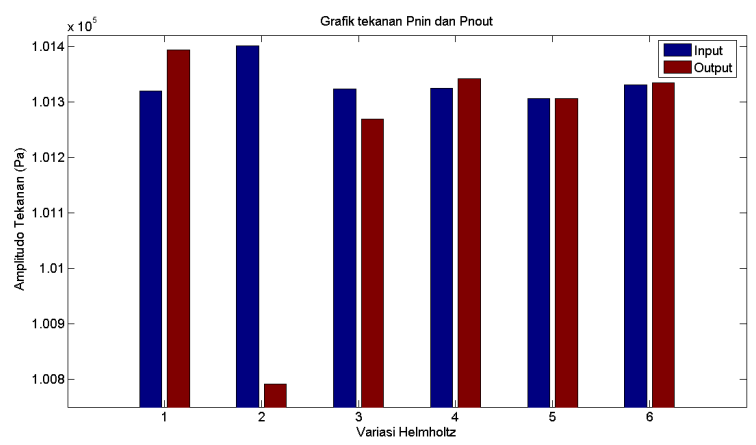

Gambar 10. Grafik rata-rata tekanan input (Pnin) dan output (Pnout) pada setiap variasi Helmholtz Resonator

Pada grafik diatas, diambil batas bawah dengan nilai $100750 \mathrm{~N} / \mathrm{m}^{2}$ dan batas atas dengan nilai $101420 \mathrm{~N} / \mathrm{m}^{2}$. Sehingga dengan jarak tersebut dapat dilihat perbedaan tinggi pada grafik diagram batang untuk rata-rata tekanan input dan output pada setiap variasi Helmholtz Resonator yang mana memiliki perbedaan nilai yang sangat tipis.

Pada grafik tersebut dapat dilihat bahwa tekanan rata-rata tertinggi berada pada variasi ke-2 untuk input yaitu sebesar $101401.37 \mathrm{~N} / \mathrm{m}^{2}$, yang mana juga merupakan yang terendah pada posisi output dengan nilai $100791.89 \mathrm{~N} / \mathrm{m}^{2}$ atau dengan terjadi penurunan sebesar $609.48 \mathrm{~N} / \mathrm{m}^{2}$ atau $0.6 \%$.

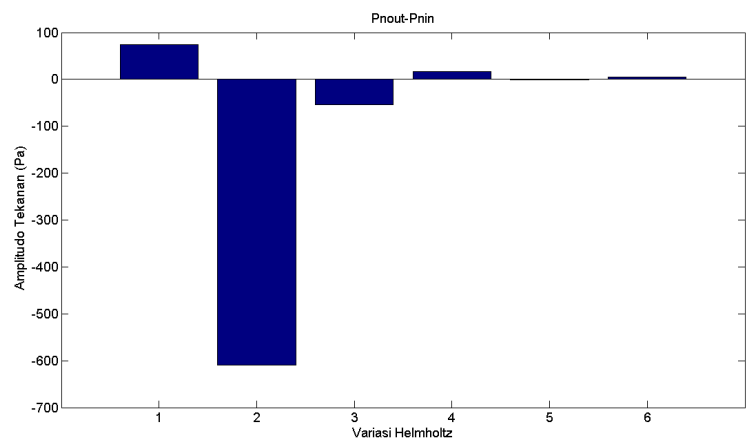

Gambar 11. Grafik selisih rata-rata tekanan output (Pnout) dan input (Pnin) pada setiap variasi Helmholtz Resonator

Pada grafik selisih tekanan output (Pnout) dan input (Pnin), kenaikan tekanan rata-rata tertinggi terdapat pada variasi pertama dari $101318.95 \mathrm{~N} / \mathrm{m}^{2} \mathrm{ke} 101392.87 \mathrm{~N} / \mathrm{m}^{2}$ dengan nilai $73.92 \mathrm{~N} / \mathrm{m}^{2}$ atau $0.07 \%$, sementara yang penurunan tekanan terbesar terdapat pada variasi kedua.
Di variasi ke-3 tekanan rata-rata masih turun di bawah 0 atau dengan nilai sebesar 54.43 $\mathrm{N} / \mathrm{m}^{2}$ atau $0.05 \%$. Sementara pada variasi Helmholtz Resonator ke-4 nilai selisih tekanan rata-rata output-input kembali naik dengan selisih sebesar $16.08 \mathrm{~N} / \mathrm{m}^{2}$ atau $0.01 \%$.

Pada variasi ke-5 tekanan rata-rata kembali turun sebesar $0.85 \mathrm{~N} / \mathrm{m}^{2}$ atau $8.46 \times 10^{-4} \%$. Dan pada variasi terakhir tekanan naik lagi sebesar $4.73 \mathrm{~N} / \mathrm{m}^{2}$ atau $4.67 \times 10^{-3} \%$.

Variasi Circular Helmholtz Resonator yang cocok bila digunakan untuk peningkatan tekanan adalah variasi pertama, ke-4 dan ke-6, dengan variasi pertama yang paling tinggi peningkatan tekanannnya. Sementara variasi Helmholtz Resonator ke-2, ke-3 dan ke-5 tidak dapat digunakan untuk keperluan peningkatan tekanan. Akan tetapi bila melihat tren grafik (4.8), ada potensi bahwa tekanan akan naik setelah variasi ke-6, sehingga perlu dilakukan penelitian lanjutan untuk mengetahui bagaimana pengaruh Circular Helmholtz Resonator bila jumlah pipa kapiler (mononeck) yang digunakan lebih dari 6 buah.

Hasil pengukuran yang diperoleh menunjukan bahwa terdapat peningkatan maupun penurunan tekanan aliran udara yang terukur pada bagian output dari sistem Circular Helmholtz Resonator yang digunakan. Penjelasan mengenai mengapa terjadinya fenomena peningkatan tekanan pada bagian keluaran dari Circular Helmholtz Resonator yang digunakan adalah suatu hal yang sudah berada diluar jangkauan tujuan dari penulisan ini.

\section{KESIMPULAN}

Berdasarkan hasil dan pembahasan yang telah diurai dapat disimpulkan bahwa Circular Helmholtz Resonator berpengaruh terhadap tekanan keluaran yang mana dapat dilihat pada perbedaan tekanan input dan output khususnya pada variasi pertama dengan satu pipa kapiler. Berdasarkan grafik output-input variasi 1, terjadi peningkatan rata-rata tekanan sebesar 73.92 $\mathrm{N} / \mathrm{m}^{2}$ atau $0.07 \%$ yang mana juga merupakan yang tertinggi dibandingkan semua variasi Helmholtz Resonator.

Sementara pada variasi ke-2 terjadi penurunan yang cukup signifikan bila dibandingkan dengan variasi pertama, yaitu $609.48 \mathrm{~N} / \mathrm{m}^{2}$ atau $0.6 \%$. Pada variasi ke-3 posisi 
output-input masih berada dibawah 0 atau minus dengan nilai sebesar $54.43 \mathrm{~N} / \mathrm{m}^{2}$ atau $0.05 \%$. Variasi ke-4 terjadi peningkatan kembali ke nilai positif $16.08 \mathrm{~N} / \mathrm{m}^{2}$ atau $0.01 \%$, variasi ke-5 turun sebesar $0.85 \mathrm{~N} / \mathrm{m}^{2}$ atau $8.46 \times 10^{-4} \%$, dan variasi ke-6 $4.73 \mathrm{~N} / \mathrm{m}^{2}$ atau $4.67 \times 10^{-3} \%$.

Turunnya tekanan rata-rata output-input pada variasi ke-2, ke-3 dan ke-5 menunjukkan bahwa Circular Helmholtz Resonator tidak efektif bila divariasikan jumlah pipa kapiler sebanyak 2, 3 dan 5 buah dalam arah longitunal, tetapi akan cocok untuk meningkatkan tekanan keluaran apabila hanya menggunakan 1, 4, dan 6 pipa kapiler (mononeck) sebagaimana hasil adanya.

\section{DAFTAR PUSTAKA}

Bortoluzzi Daniele, Vittore Cossalter, Alberto Doria. 1998. The Effect of Tunable Resonators On The Volumetric Efficiency Of An Engine. SAE technical paper series 98MSE-10 NO. 983045.

Brennen, Christopher Earls. 1994. Hydrodynamics Of Pumps. Concepts NREC, ISBN 0-933283-07-5.

Dupère, I. D. J., and Dowling, A. P. 2005. The Use of Helmholtz Resonators in a Practical Combustor. Journal of Engineering for Gas Turbines and Power, Vol. 127, pp. 268-275.

Everest, F. Alton. 2001. The Master Handbook Of Acoustics. Fourth Edition. New York: McGraw-Hill.

Fox, W. Robert, McDonald, Alan T., and Pritchard, Philip J. 2003. Introduction to Fluid Mechanics. Sixth Edition. Manhattan: John Wiley \& Sons, Inc.

Hadi, A., Wardana, ING., and Sutikno, Djoko. 2011. The Energy Flux Different Stability Estimation Of Hydraulic Flow In A Horizontal Pipeline With Longitudinal Grooves Number Variation. Jurnal Rekayasa Mesin, Vol.2: 165-174.

Hanriot, S. M, Valle, R.M, Sodré, J. R., and Queiróz, J. M.. 2013. Helmholtz Resonator Effects On Engine Intake Air Mass Flow Rate. International Congress of Mechanical
Engineering - COBEM 2013, ISSN 21765480.

Matko, D., Geiger, G., and Werner, T. 2001. Modelling of the Pipeline as a Lumped Parameter System. Original scientific paper ATKAAF 42(3-4), 177-188 (2001), ISSN 0005-1144.

Petrovsky, Nikolai Viktorovich. 1966. Marine Internal Combustion Engines. MIR Publishers: Moscow. Page: 199-201.

Potter C. Merle and Wiggert C. David. 2008. Mekanika Fluida. Penerbit Erlangga: Jakarta.

Potul, Shrinath, Rohan Nachnolkar and Sagar Bhave. 2014. Analysis Of Change In Intake Manifold Length And Development Of Variable Intake System. Journal Of Scientific \& Technology Research Volume 3, Issue 5, ISSN 2277-8616: 223-228.

Quarteroni, Alfio, Riccardo Sacco and Fausto Saleri. 2006. Numerical Mathematics: Second Edition. Springer: Milan.

Selamet, A., Dickey, N. S., Radavich, P. M., and Novak, J. M. Theoretical, Computational and Experimental Investigation of Helmholtz Resonators: One-Dimensional Versus Multi-Dimensional Approach. SAE 940612.

Shi, Xiaofeng, Cheuk M. Mak, and Jun Yang. 2013. Attenuation Performance of a SemiActive Helmholtz Resonator in a Grazing Flow Duct. Journal of Acoustics, 3, 25-29.

Wan, D., and Soedel, D. T. 2004. Two Degree of Freedom Helmholtz Resonator Analysis. SAE 2004-01-0387. 